\title{
Polysaccharide Storage Myopathy (PSSM) - a genetically determined disease in horses
}

\author{
Flavius BANYAI ${ }^{1) *}$, Augustin VLAIC ${ }^{1)}$ \\ ${ }^{1)}$ Department of Genetics, Faculty of Animal Science and Biotechnologies, University of Agricultural \\ Sciences and Veterinary Medicine of Cluj-Napoca, 3-5 Manastur Street, 400372, Cluj-Napoca, Romania \\ *Corresponding author, e-mail: flaviuss11@gmail.com
}

Bulletin UASVM Animal Science and Biotechnologies 72(2) / 2015

Print ISSN 1843-5262; Electronic ISSN 1843-536X

DOI:10.15835/buasvmcn-asb:11421

\begin{abstract}
In Romanian horse breeds there is little information about Polysaccharide Storage Myopathy disease and therefore the objective of this study was to do a first evaluation of two indigenous horse breeds for presence of polymorphism in the GYS1 gene, associated with the disease. In this purpose, a number of 14 biological samples were collected from two breeds: Semigreu Romanesc and Lipitan. The genomic DNA was isolated from hair samples with Quick-gDNA Mini Prep kit, according to the manufacturer's protocol. A $229 \mathrm{bp}$ fragment, targeting the polymorphic region of GYS1 gene, was amplified with a set of specific primers and the PCR products were digested with $\mathrm{HpyCH} 4 \mathrm{~V}$ restriction enzyme. The resulting fragments were separated in $3 \%$ agarose gel. Two fragments, of 151 and $78 \mathrm{bp}$, which correspond to the GG genotype, were identified, while four fragments $(151,97,78$ and 54 bp) were obtained in the case of heterozygous AG genotypes. All analysed Lipitan horses were homozygous for the $\mathrm{G}$ allele, while all Semigreul Romanesc horses were heterozygous, carrying the A allele which are associated with PSSM. To establish more accurate results in Romanian horse breeds, further studies, on a larger number of horses, are needed.
\end{abstract}

Keywords: horse, polysaccharide storage myopathy, GYS1 mutation, PCR-RFLP

\section{INTRODUCTION}

Horses have been domesticated for thousands of years, and modern breeds have been established by selection for a variety of athletic, physical and behavioural traits. In horses, as in other animal species, line breeding to propagate desirable traits has coincidentally also propagated deleterious traits. (Valberg et al., 1999; Firshman et al., 2005)

One such undesirable trait is Polysaccharide Storage Myopathy (PSSM), a debilitating and potentially life-threatening glycogen storage disease that occurs in several genetically diverse breeds of horses. (Valberg et al., 1992; Firshman et al., 2003). Polysaccharide Storage Myopathy (PSSM) in horses is characterized by abnormal glycogen accumulation in skeletal muscle and muscle damage with exertion.
Clinical findings consistent with PSSM were first reported in the early 1900s in working Draft horses that developed exertional rhabdomyolysis when returning to work after several days of rest (Carlstrom, 1932). However, PSSM was not recognized as a skeletal muscle glycogenosis until 1992 (Valberg et al., 1992). Today, as many as 36\% Draft horses and 10\% of Quarter Horses have PSSM (McCue et al., 2007; Firshman et al., 2005).

The phenotypic expression of PSSM ranges from muscle atrophy and progressive weakness in Draft horse breeds to muscle soreness and gait abnormalities in Warmblood breeds, and acute exertional rhabdomyolysis in Quarter Horses (McCue et al., 2008). The severity of clinical signs in PSSM ranges from muscle cramping and stretching out to severe muscle pain and myoglobinuria 
and occasionally the complete inability to rise (McCue et al., 2008). Although PSSM is clinically well-recognized and common, its metabolic basis has remained a mystery for over a hundred years (McCue et al., 2008). Diagnostic of PSSM is a gluteal muscle biopsy, but which is not a $100 \%$ sensitive test.

A genome wide association study identified a G/A substitution in GYS1 gene as a candidate for PSSM in horses (McCue et al., 2008). Because in Romanian horse breeds there is little or shallow information about Polysaccharide Storage Myopathy disease, the objective of this study was to do a first evaluation of two indigenous horse breeds, for presence of this polymorphism in the GYS1 gene.

\section{MATERIALS AND METHODS}

A number of 14 biological samples (hair) were collected from two breeds (Semigreu Romanesc and Lipitan) under the proper conditions, using sterile gloves.

The genomic DNA was isolated with the QuickgDNA Mini Prep kit (Zymo Research Corporation), according to the manufacturer's protocol. DNA quality and quantity of each sample were assessed spectro-photometrically on NanoDrop ND 1000 (NanoDrop Technologies, USA).

A $229 \mathrm{bp}$ fragment targeting the polymorphic region of GYS1 gene was amplified with a set of specific primers, reported before by McCue and colleagues (2008). Genomic DNA was amplified by polymerase chain reaction (PCR). The forward/reverse primers used have the following sequences: 5'TGA AAC ATG GGA CCT TCT CC / 5'AGC TGT CCC CTC CCT TAG AC).
The PCR reaction was performed in the 25 $\mu$ final volume with MyTaq2x RedMix (Bioline) under the following conditions:

MyTaq 2x Ready Rection Mix - 12,5 $\mu \mathrm{l}$

Primes (GYS forward and GYS reverse) - $1 \mu \mathrm{l}$ each PCR grade $\mathrm{H}_{2} \mathrm{O}-8,5 \mu \mathrm{l}$

DNA - $2 \mu \mathrm{l}$

The correct amplification of the $229 \mathrm{bp}$ fragment in the PCR reactions was analysed in 1\% agarose gel, before digestion assay (fig. 1).

After PCR, $25 \mu \mathrm{l}$ of PCR products were digested with $5 \mathrm{U} / \mu \mathrm{l}$ of $\mathrm{HpyCH} 4 \mathrm{~V}$ restriction enzyme (New England Biolabs), $2 \mathrm{~h}$ at $37^{\circ} \mathrm{C}$, and the resulting fragments were separated in 3\% agarose gel, stained with 1xSybrSafe (Applied Biosystems). Electrophoresis was performed in 1x TBE buffer under constant conditions (70V), for $2 \mathrm{~h}$. After the electrophoresis, the products were analysed with Molecular Imager Gel Doc (BioRad, USA).

\section{RESULTS AND DISCUSSION}

In the agarose gel, two fragments, of 151 and $78 \mathrm{bp}$ that correspond to homozygous GG genotypes were detected, while four fragments $(151,97,78$ and $54 \mathrm{bp})$ were obtained in the case of heterozygous (AG) genotypes. All analysed Lipitan horses were homozygous for the G allele (Fig.2), while all Semigreul Romanesc horses were heterozygous, carriers of A allele (fig.3) which is associated with PSSM.

Analysing 750 horses with PSSM, from 15 different breeds (Quarter, Paint, Appaloosa, Draft, Morgan, etc.), McCue et al., 2007 found 356 individuals carrying the A allele, either the homozygous or the heterozygous form, with normal G allele.

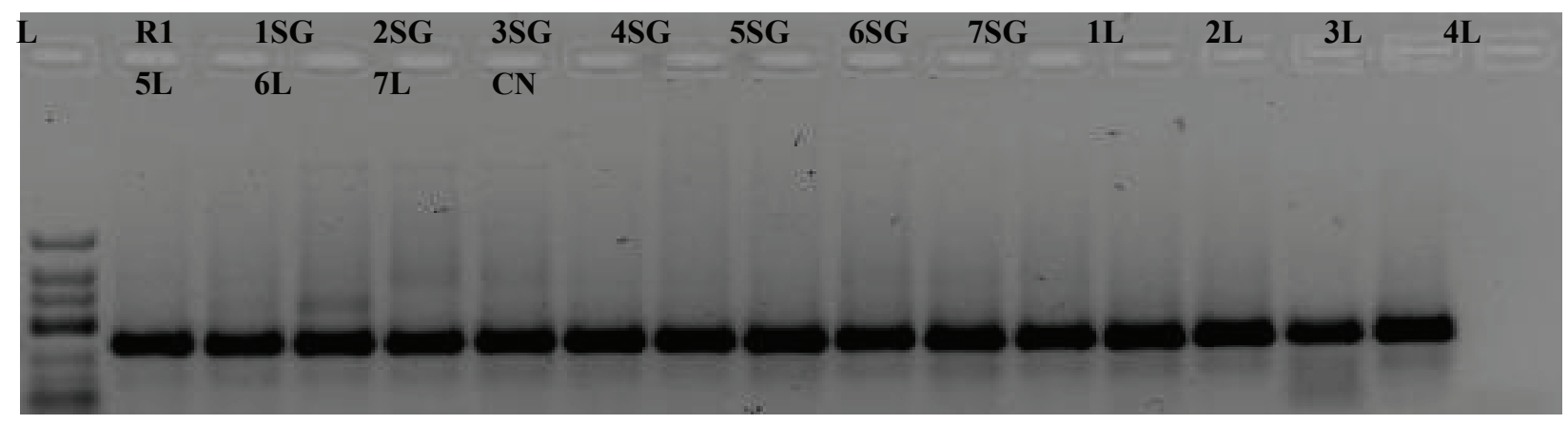

Fig.1. Undigested PCR products (229 bp) Note: CN- negative control, L- 25- 700 pb GeneRuler (Thermo-Scientific) 


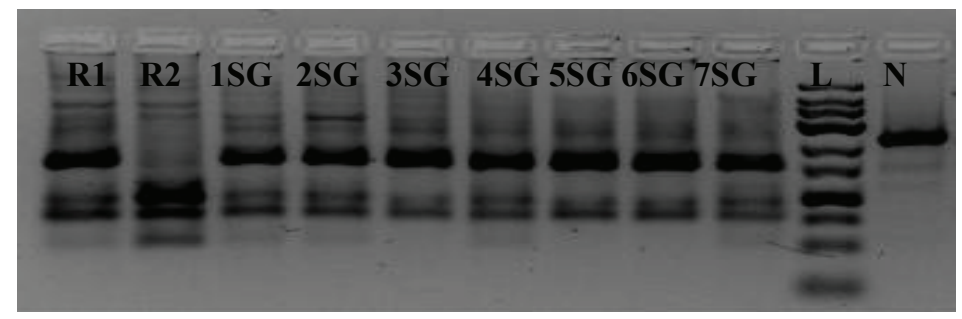

Fig.2. PCR products digested with $\mathrm{HpyCH} 4$ restriction enzyme in Semigreul Romanesc breed. R1- Reference (PSSM horse) 1 heterozygous AG genotypes; R2- Reference (PSSM horse) 2 homozygous AA genotypes, L- 25700 pb GeneRuler (Thermo-Scientific), N - Undigested PCR products (229 bp), CN- negative control

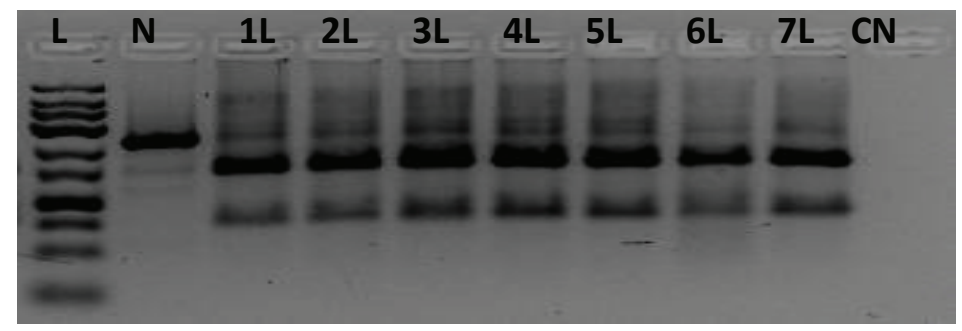

Fig.3. PCR products digested with HpyCH4 restriction enzyme in Lipitan breed. R1- Reference (PSSM horse )

1 heterozygous AG genotypes; R2- Reference (PSSM horse ) 2 homozygous AA genotypes, L- 25- 700 pb GeneRuler (Thermo-Scientific), N - Undigested PCR products (229 bp), CN- negative control

A similar, but more complex study was carried out in Quarter breed. 99 individuals, previously diagnosed with PSSM, were analysed for presence/ absence of the mutation in the GYS1 gene. Out of the 99 horses, 72 were homozygous for A allele (CAT codon /Histidine), while 5 were heterozygous, carrying the A allele, but surprisingly, 22 of the horses were homozygous for normal $\mathrm{G}$ allele (CGT codon /Arginine). After these results, other 92 healthy horses (control group) were subjected to the same analysis, and the results revealed that 88 individuals were homozygote for normal $\mathrm{G}$ allele, while 4 horses were heterozygote (AG). Based on these genotypes, penetrance of the $\mathrm{H} / \mathrm{H}$ and of the $\mathrm{R} / \mathrm{H}$ genotype are 1.0 and 0.95 , respectively. However, a gluteal muscle biopsy is not a $100 \%$ sensitive diagnostic test, and the 4 control horses that were heterozygous for the $\mathrm{H}$ allele may have been false negatives and represented phenotypic error. Segregation of the $\mathrm{H}$ allele with PSSM was confirmed in a resource pedigree in this study (McCue et al., 2008).

\section{CONCLUSION}

The horses included in my study were randomized selected from different farms, without any clinical sign of PSSM. All analysed Lipitan horses were homozygous for the normal G allele
(GG), while all Semigreul Romanesc horses were heterozygous for the mutant A allele (AG). From these points of view, further studies, on a larger number of horses, are needed to establish with high accuracy the frequency of this mutation in Romanian breeds.

Acknowledgements: This paper was published under the frame of European Social Found, Human Resources Development Operational Programme 2007-2013, project no. POSDRU/159/1.5/S/132765.

\section{REFERENCES}

1. Carlstrom B. (1932). Uber die atiologie und pathogenese der kreuzlahme des pferdes (Hemaglobinaemia paralytica) Scandinav Archiv, 62:1-62.

2. Firshman AM, Valberg SJ, Bender JB, Finno CJ. (2003), Epidemiologic characteristics and management of polysaccharide storage myopathy in Quarter Horses. Am J Vet Res.;64:1319-1327

3. Firshman AM, Baird JD, Valberg SJ. (2005) Prevalences and clinical signs of polysaccharide storage myopathy and shivers in Belgian draft horses. J Am Vet Med Assoc. 227:1958-1964.

4. McCue ME, Valberg SJ. (2007) Estimated prevalence of polysaccharide storage myopathy among overtly healthy Quarter Horses in the United States. J Am Vet Med Assoc.231:746-750. 
5. McCue ME, Valberg SJ., Miller, MB, Wade C, Dimauro S, Akman HO, Mickelson JR. (2008), Glycogen synthase (GYS1) mutation causes a novel skeletal muscle glycogenosis, Genomics, 91: 458-466.

6. Valberg SJ, Cardinet GH, Carlson GP, DiMauro S. (1992). Polysaccharide storage myopathy associated with recurrent exertional rhabdomyolysis in horses. Neuromuscul Disord., 2:351-359.

7. Valberg SJ, MacLeay JM, Billstrom JA, Hower-Moritz MA, Mickelson JR. (1999). Skeletal muscle metabolic response to exercise in horses with 'tying-up' due to polysaccharide storage myopathy. Equine Vet J.31:43-47. 